\title{
Efficacy of cytotoxic agents used in the treatment of testicular germ cell tumours under normoxic and hypoxic conditions in vitro
}

\author{
S Koch ${ }^{1,2}$, F Mayer ${ }^{1,2}$, F Honecker', M Schittenhelm' and C Bokemeyer ${ }^{*, 1}$ \\ 'Department of Oncology, Hematology, Immunology, and Rheumatology, Medizinische Klinik, University of Tübingen Medical Center, Otfried-Müller-Str. \\ 10, Tübingen 72076, Germany
}

\begin{abstract}
Platinum-based chemotherapy is the main treatment element to achieve cure for patients with metastatic germ cell tumours. Drug resistance in testicular germ cell tumours (TGCTs) is rare and the reasons are not fully understood. While recent investigations have indicated decreased efficacy of chemotherapy in several tumour types under hypoxic conditions, this aspect has not been investigated in TGCTs so far. Furthermore, for cisplatin - the most active drug in this disease - controversial effects of hypoxia on cytotoxic efficacy have been reported. The relative efficacy of cytotoxic agents for the treatment of TGCT patients was studied in three different cell lines derived from human embryonal carcinomas (EC) in an in vitro hypoxia model. NT2, 2102 EP, and NCCIT were tested for their sensitivity towards cisplatin, etoposide, bleomycin, 4-OOH-ifosfamide, carboplatin, paclitaxel, gemcitabine, oxaliplatin, irinotecan, and mitomycin $C$ under normoxic and hypoxic conditions using the MTT assay. Inhibitory concentrations $\mathrm{IC}_{50}$ of the tested agents under both conditions were compared. Selected results were confirmed by flow-cytometric assessment of the apoptotic index. In all cells, doubling times were prolonged in hypoxia (NT2<NCCIT $<2102$ EP). All drugs were less effective under hypoxic conditions, including mitomycin $C$ (eg, l.6-fold increase of $\mathrm{IC}_{50}$ in hypoxia compared to normoxia for NT2) and cisplatin (eg, NT2: two-fold increase). The relative effect of hypoxia on the $\mathrm{IC}_{50}$ depended mainly on the cell line, and to a lesser extent on the drug. The results indicate that the reduced cell proliferation in hypoxia might be an important factor, but not the only determinant of a reduced cytotoxicity. In view of the broad spectrum of drugs with different modes of action tested, the relative resistance cannot be mediated by substance-specific resistance mechanisms like hypoxia-induced upregulation of P-glycoprotein or increased DNA-repair capacity, since many unrelated drugs were affected to a comparable extent in their efficacy by hypoxia. This study also provides the rationale to test the hypothesis whether improving tumour oxygenation by raising haemoglobin concentrations, for example, with erythropoietin in patients with TGCTs receiving chemotherapy may improve the outcome.
\end{abstract}

British Journal of Cancer (2003) 89, 2 I33-2139. doi:I0.1038/sj.bjc.6601375 www.bjcancer.com

(C) 2003 Cancer Research UK

Keywords: testicular germ cell tumours (TGCTs); cytotoxic drugs; normoxia; hypoxia; in vitro

Testicular germ cell tumours (TGCTs) are highly sensitive to cisplatin-based combination chemotherapy, and most patients with this disease can be cured today. Nevertheless, $10-15 \%$ of patients with metastatic disease will not achieve a disease-free survival with currently available treatment strategies, and finally die of their disease. The reasons for intrinsic or subsequently developed treatment resistance in these patients have not yet been fully explored (Mayer et al, 2003). A reduced intratumoral oxygen tension (hypoxia) has been reported in a variety of malignant tumours (Vaupel and Hoeckel, 1998; Semenza, 2000), and may limit the effectiveness of cytotoxic drugs. A positive correlation between the intracellular oxygen tension $\left(\mathrm{pO}_{2}\right)$ and the efficacy of a radiotherapy has been described as early as 1931 (Mottram, 1931). These experimental data are endorsed by more recent clinical findings in patients with cancer of the uterine cervix, and head and

\footnotetext{
*Correspondence: Dr C Bokemeyer;

E-mail: carsten.bokemeyer@med.uni-tuebingen.de

${ }^{2}$ Contributed equally to this work

Received 9 May 2003; revised 9 September 2003; accepted 17

September 2003
}

neck tumours undergoing radiotherapy (Hoeckel et al, 1996; Nordsmark et al, 1996). The intratumoral oxygen tension depends at least partly on the haemoglobin level of the blood (Vaupel and Hoeckel, 1998; Becker et al, 2000).

Under hypoxic conditions, proteins like the vascular endothelial growth factor (VEGF) and the hypoxia-inducible factor 1 alpha (HIF- $1 \alpha$ are upregulated in cancer cells (Zhong et al, 1999; Kondo et al, 2000; Cooke et al, 2001; López-Barneo et al, 2001). Induction of antiapoptotic proteins like Bcl-2 or of the multidrug resistance gene (MDR1) product P-glycoprotein is associated with HIF- $1 \alpha$ overexpression, and may lead to resistance against chemotherapeutic agents (Goldstein, 1996; Zhong et al, 1999; Kinoshita et al, 2001; Comerford et al, 2002). The loss of apoptotic mechanisms (deprivation of p53) and loss of DNA mismatch repair (MMR) in hypoxia render cells both hypersensitive to acquire microsatellite instability and to the development of drug resistance (Lin et al, 2000, 2001; Kondo et al, 2001).

Most cytotoxic agents show a positive relation between oxygen tension and efficacy in cell culture. For mitomycin C, higher efficacy in hypoxia has been reported (Kennedy et al, 1983; Luk et al, 1990; Yamagata et al, 1992; Sanna and Rofstad, 1994). For cisplatin, the most active drug for TGCTs, the results reported are 
contradictory, but seem to indicate an enhanced drug activity under hypoxic conditions in various models (Liang, 1996; Skov et al, 1998; Kovacs et al, 1999). Other cytotoxic drugs with described clinical activity in refractory germ cell tumours, such as paclitaxel, gemcitabine and oxaliplatin, have not yet been tested for their activity under hypoxia in vitro. In addition, both the choice of the specific chemotherapeutic agent as well as the tumour type may influence the relative impact of hypoxia in the treatment setting.

Erythropoietin (epoietin) offers the chance to effectively ameliorate anaemia in cancer patients receiving chemotherapy (Cella et al, 2003). Next to a proven benefit regarding quality of life, epoietin might potentially affect the efficacy of the anticancer treatment used by raising the $\mathrm{O}_{2}$ in tumour tissues. In order to provide the preclinical rationale for a clinical study with chemotherapy and epoietin in patients suffering from GCTs, we have investigated the in vitro efficiency of cytotoxic agents with different modes of action such as alkylating agents (eg, ifosfamide), platin derivatives, antibiotics (mitomycin C, bleomycin), gemcitabine, topoisomerase I (irinotecan) and II (etoposide) inhibitors, and the taxane derivative paclitaxel under normoxic and hypoxic conditions in established TGCT cell lines. Furthermore, the model system chosen here is used to discuss the relative efficacy of different cytotoxic agents in relation to the most effective drug cisplatin.

\section{MATERIALS AND METHODS}

\section{Anticancer drugs}

The drugs used were: cisplatin (CDDP; Bristol-Myers Squibb, München, Germany), oxaliplatin (Sanofi-Synthelabo GmbH, Berlin, Germany), carboplatin (Bristol-Myers Squibb), gemcitabine (Lilly Deutschland, Bad Homburg, Germany), etopophos (etoposide phosphate, VP-16; Bristol-Myers Squibb), bleomycin (Mack, Illertissen, Germany), mitomycin C (medac, Wedel, Germany), irinotecan (Aventis Pharma, Frankfurt/M., Germany), and 4hydroperoxyifosfamide (4-OOH-ifosfamide; Asta Medica, Frankfurt/M., Germany). These agents were dissolved in distilled water. The semisynthetic agent paclitaxel (Sigma, Deisenhofen, Germany) from Taxus baccata was dissolved in DMSO (Sigma) and used without exceeding a final concentration of DMSO $0.1 \%(\mathrm{v} / \mathrm{v})$ which by itself is not a toxic concentration for the cell lines studied.

\section{TGCT cell lines and culture conditions}

Three established TGCT cell lines derived from human embryonal carcinomas were tested for their sensitivity towards different chemotherapeutic agents. The TGCT cell line NTera-2 (NT2/D1, a cell line known to be able to differentiate into neurons); ATCC CRL-1973 used in this study was maintained in DMEM with $4.5 \mathrm{gl}^{-1}$ glucose and stable glutamine (Invitrogen, Karlsruhe, Germany), the 2102 EP cell line (Wang et al, 1981) and NCCIT (ATCC CRL-2073) were cultured in DMEM/F-12 with $2 \mathrm{mM} \mathrm{L}$ glutamine (Biochrom). All cell lines were grown with the addition of $10 \%$ fetal calf serum (FCS; Biochrom, Berlin, Germany) and $1 \%$ penicillin/streptomycin (Biochrom) at $37^{\circ} \mathrm{C}$ in a humid atmosphere containing $5 \% \mathrm{CO}_{2}$ as monolayers in $75 \mathrm{~cm}^{2}$ cell culture flasks.

\section{Cell proliferation in normoxia $v s$ hypoxia}

For the assessment of doubling times, the cells were cultured in normoxic $\left(20 \% \mathrm{O}_{2}\right)$ and hypoxic (continuous flow of $0.11 \mathrm{~min}^{-1}$ of a mixture of $94 \% \mathrm{~N}_{2}, 5 \% \mathrm{CO}_{2}$, and $1 \% \mathrm{O}_{2}$ ) conditions. Briefly, individual cells were spread out in six-well plates and viable cells were counted in their logarithmic growth phase after 48 and $70 \mathrm{~h}$ to calculate the population-doubling times under both conditions by trypane blue ( $0.4 \%$; Sigma) exclusion.

For determination of cell cycle progression, NT2 and NCCIT cells were grown in $25 \mathrm{~cm}^{2}$ culture flasks in normoxia and hypoxia for $48 \mathrm{~h}$. Further processing was performed according to the method of Nicoletti et al (1991). In brief, the supernatant and adherent cells were harvested, washed, and suspended in $0.5 \mathrm{ml}$ hypotonic lysis buffer $(0.1 \%$ sodium citrate, $0.1 \%$ Triton X-100) containing $25 \mu \mathrm{l}$ of a $1 \mathrm{mg} \mathrm{m}^{-1}$ propidium iodide (PI) stock solution $\left(50 \mu \mathrm{g} \mathrm{ml}^{-1}\right.$ final concentration). Analysis of the cell cycle phase was performed by flow cytometry on a FACScalibur (Becton Dickinson, Heidelberg, Germany), using the CellQuest analysis software.

\section{Determination of $\mathrm{pH}$ value of the medium for untreated cells}

NT2 and NCCIT cells were cultured with $10 \mathrm{ml}$ complete medium in $25 \mathrm{~cm}^{2}$ cell culture flasks under normoxic and hypoxic conditions. After $72 \mathrm{~h}$, the $\mathrm{pH}$ of the cell medium was measured using the $\mathrm{pH}$ meter model $\mathrm{pH} 330$ (WTW, Weilheim, Germany) and compared with $37^{\circ} \mathrm{C}$ annealed normoxic and hypoxic medium without cells.

\section{In vitro drug-sensitivity assay}

The MTT assay was performed as previously described (Sieuwerts et al, 1995). In brief, the cell lines NT2, $2102 \mathrm{EP}$, and NCCIT were rinsed with phosphate-buffered saline (PBS, Biochrom), trypsinised and resuspended in $1 \mathrm{ml}$ of the appropriate culture medium, to count the cells in a haemacytometer chamber. In all, $4 \times 10^{3}$ cells/well were seeded in 96-well plates to ensure their logarithmic growth. Cells were allowed to adhere over night, serial dilutions of the chemotherapeutic agents were added to octuplicate wells at concentrations from $1 \mathrm{~nm}$ to $0.1 \mathrm{~mm}$. The cells were exposed to the drugs for additional $72 \mathrm{~h}$ under normoxic and hypoxic conditions. Additionally, NT2 and NCCIT cells were treated with mitomycin $\mathrm{C}$ for $72 \mathrm{~h}$ under hypoxic conditions using culture medium adjusted to $\mathrm{pH}$ 6.5.

After this, the drug-containing medium was removed and $0.2 \mathrm{ml}$ MTT solution (final concentration: $0.5 \mathrm{mg} / \mathrm{mL}$ MTT; Sigma) was added in ther $\backslash$ medium. The plates were incubated for $2 \mathrm{~h}$ and then the medium was removed, $0.1 \mathrm{ml}$ DMSO was added, the plates agitated for $15 \mathrm{~min}$ and the optical density read using a photometer (MRX Revelation, Dynex Technologies, VWR International, Bruchsal, Germany) at $570 \mathrm{~nm}$.

All experiments were replicated separately twice or more if the values of increase in $\mathrm{IC}_{50}$ in hypoxia compared to normoxia were greater than $20 \%$, to ensure reproducibility. The results are expressed as drug concentrations that inhibit cell growth by $50 \%$ (inhibitory concentration; $\mathrm{IC}_{50}$ ). The $\mathrm{IC}_{50}$ of the tested agents under both conditions were estimated graphically from the doseresponse curves and compared. The relative increase in $\mathrm{IC}_{50}$ in normoxia $v s$ hypoxia was assessed.

\section{Induction and quantification of apoptotic cells}

In all, $1 \times 10^{5}$ cells/well for normoxia and $2 \times 10^{5}-4 \times 10^{5}$ cells/well for hypoxia were seeded in six-well plates. After overnight preincubation, serial dilutions of cisplatin and paclitaxel were added to the medium in chosen concentrations for NT2 and 2102 EP cells. Annexin-V labelling of the cells was performed as recommended by the manufacturer (Roche Diagnostics; Mannheim, Germany). In brief, after $72 \mathrm{~h}$ floating, adherent cells were harvested using trypsine-EDTA solution after PBS washing. The cell suspension was spun down and the cell pellet was resuspended in $0.1 \mathrm{ml}$ of a marker solution $(2 \mu \mathrm{l}$ Annexin-V-Fluos $(50 \times$ 
A

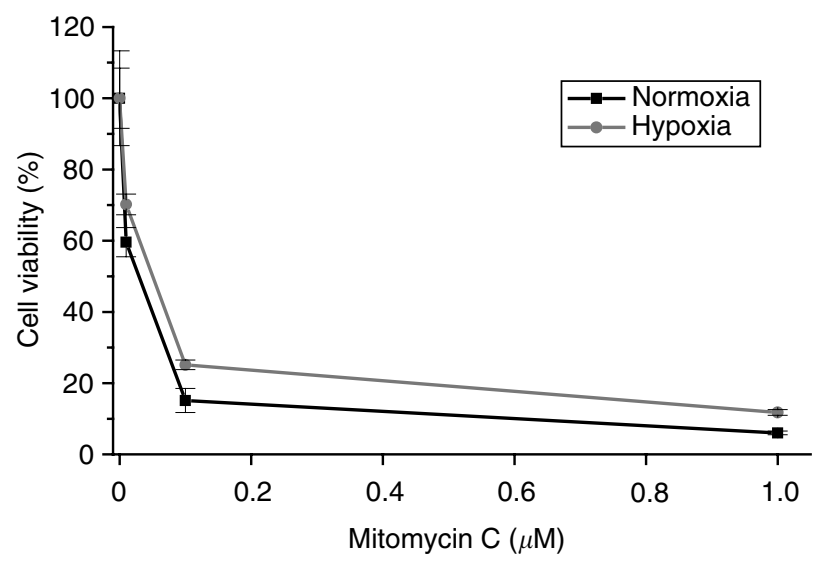

B

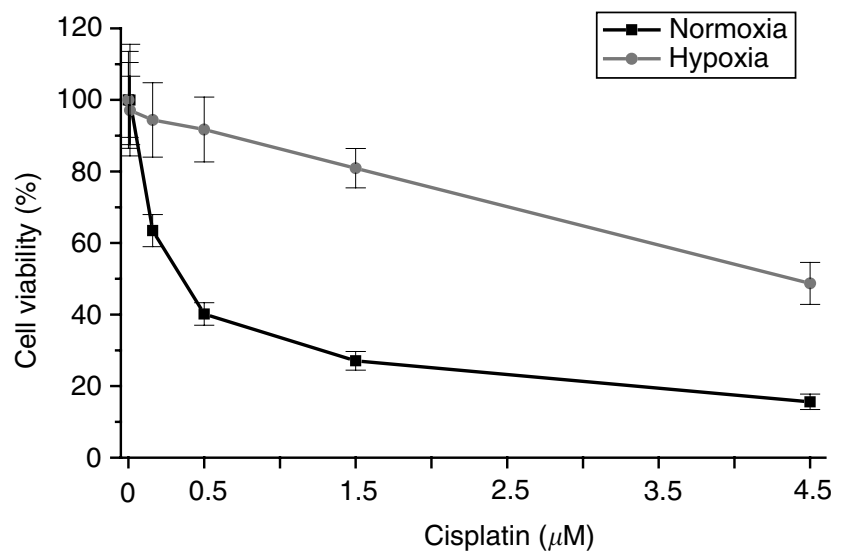

Figure I Cell viability, expressed as percent of the control (\%means \pm s.d., which is indicated by the bars of the line plots) of EC cells in culture after $72 \mathrm{~h}$. (A) NT2 cells treated with mitomycin C. (B) 2102 EP cells treated with cisplatin. Note that both drugs, mitomycin $C$ and cisplatin, are less effective in hypoxia.

colorimetric MTT assay were verified by flow cytometry. Viable cells (exclusion of PI and Annexin) and cells killed by cisplatin and paclitaxel (exclusion of PI, binding of Annexin) after a $72 \mathrm{~h}$ drug exposure of NT2 and 2102 EP were analysed by quantitating PI/ Annexin-V labelling. The flow-cytometric results confirmed that cisplatin and paclitaxel are more effective in normoxia. For cisplatin, the relative resistance increased two-fold as measured by MTT, and 3.6-fold as assessed by FACS in NT2 cells in hypoxia compared to normoxia.

\section{DISCUSSION}

In this in vitro study, three different TGCT cell lines were used to investigate the efficacy of several cytotoxic agents. The cell lines differed in their relative sensitivity to cisplatin by factor of 4 . For oxaliplatin, the activity was almost similar in NT2 (cisplatinsensitive) and 2102 EP (cisplatin-resistant) cells, and increased only by a factor 2 in NCCIT (cisplatin-resistant) cells. These in vitro data corroborate our previous clinical data describing a palliative oxaliplatin-based treatment option in patients with cisplatin-refractory germ cell cancer (Kollmannsberger et al, 2002). Carboplatin showed cross-resistance to cisplatin and a markedly lower activity on an equimolar level. Among the various
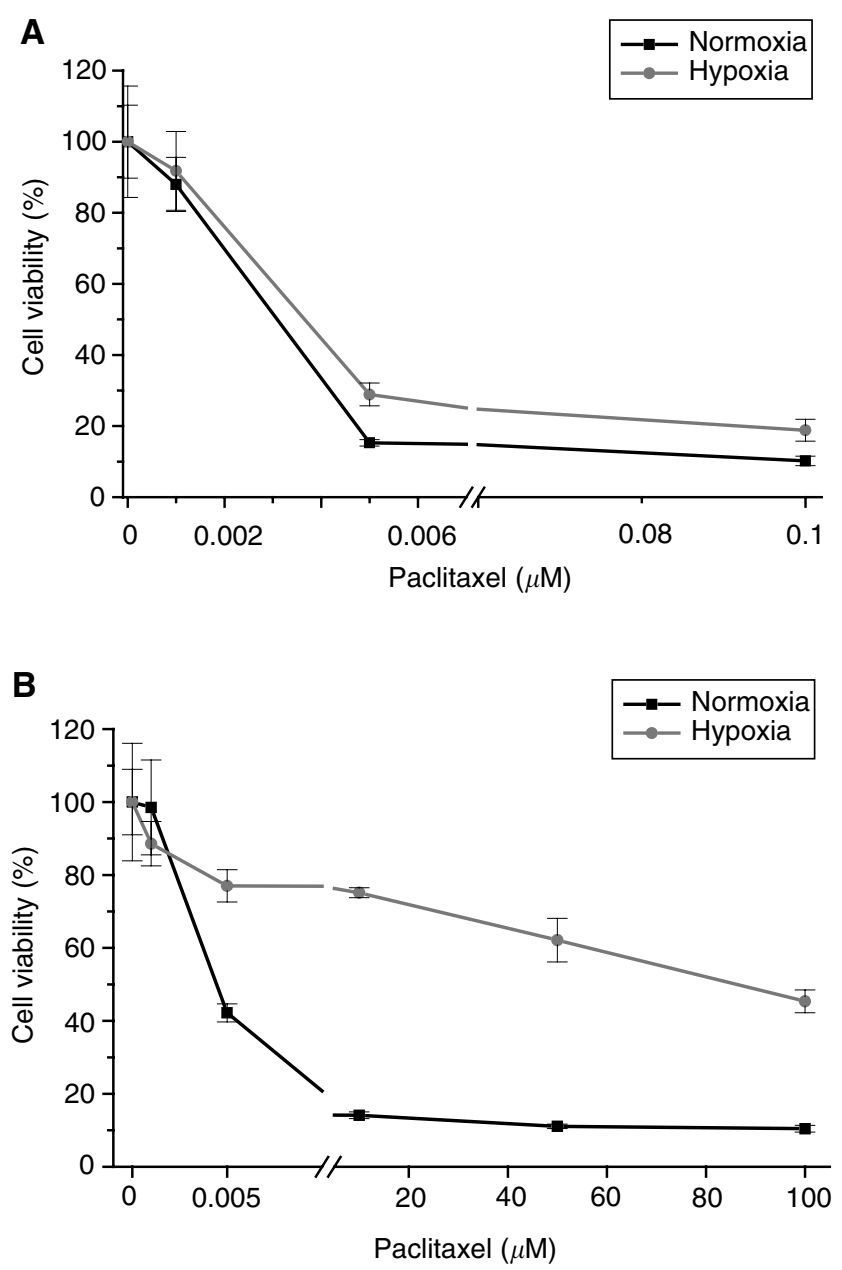

Figure 2 Cell viability, expressed as percent of the control (\%means \pm s.d., which is indicated by the bars of the line plots) of EC cells in culture after $72 \mathrm{~h}$ treated with paclitaxel. (A) NT2 cells. (B) NCCIT cells.

agents used in this study, paclitaxel was very active in all cells, with no relative increase in $\mathrm{IC}_{50}$ values in cells where cisplatin was clearly less active. In line with this finding, Motzer et al (1995) described a marked efficacy of this drug in a teratocarcinoma cell line, particularly in cisplatin-resistant cells.

The main objective of this in vitro study was to investigate the relative efficacy of several chemotherapeutic agents used in the treatment for metastatic TGCTs during normoxic and hypoxic conditions. The oxygen content used in hypoxia models ranges from $<0.1$ to $1 \%$. Culturing of the different GCT-derived cell lines in an atmosphere containing $1 \%$ oxygen induced a growth arrest and, in case of NT2 and 2102 EP cells, also cell deaths. Therefore, lowering the oxygen content further would have precluded a meaningful analysis due to lack of viable cells. To our knowledge, there are no data on the physiologic oxygen content in primary TGCTs or in metastases. Frequently encountered widespread necrotic areas suggest an insufficient blood supply and consequently hypoxia at least in some areas of these tumours.

Hypoxia has been shown to induce resistance against various agents and radiation (Brown and Giaccia, 1998; Hoeckel and Vaupel, 2001; Koukourakis et al, 2001; Vaupel et al, 2001). Conflicting data have been described for cisplatin, the most active drug in the treatment of TGCTs (Liang, 1996; Skov et al, 1998; Kovacs et al, 1999). The impact of hypoxia on the efficacy of the chemotherapeutic agents cisplatin, etoposide, bleomycin, ifosfa- 
A
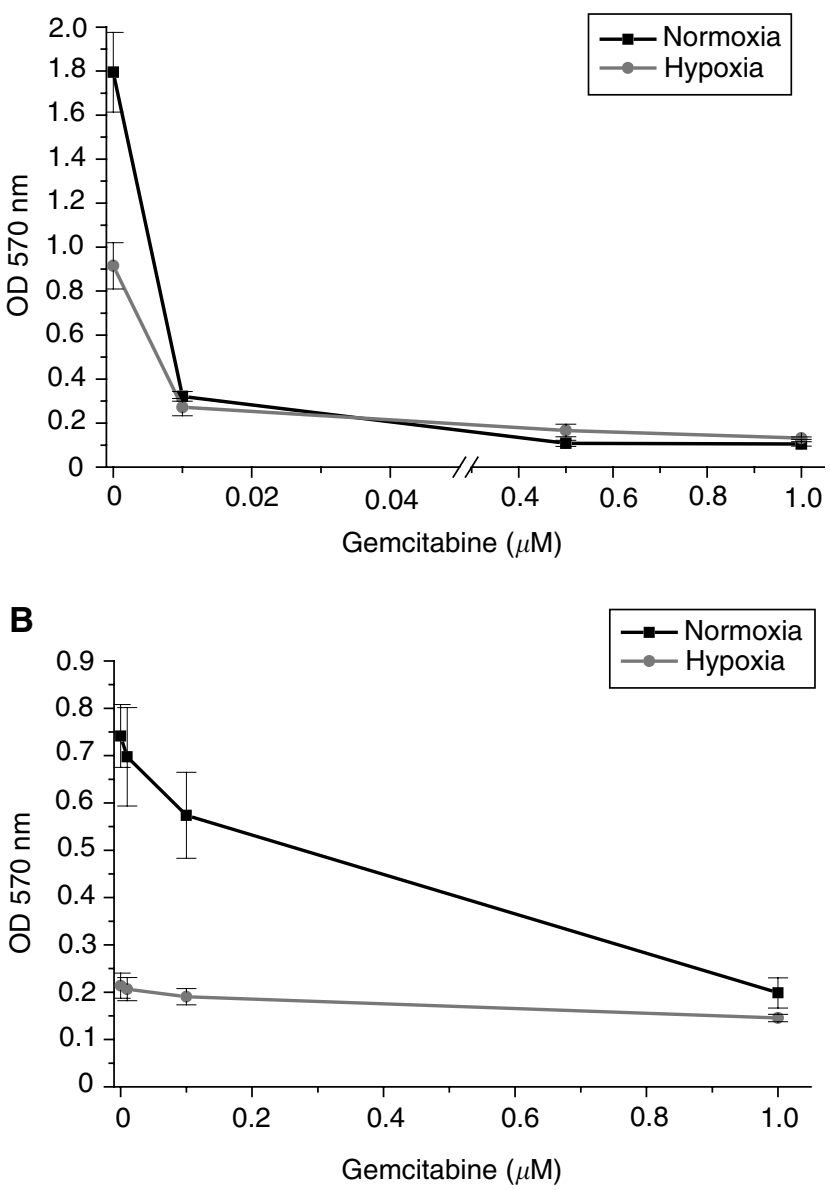

Figure 3 Cell growth, expressed as optical density at $570 \mathrm{~nm}$ (ODmeans \pm s.d., which is indicated by the bars of the line plots) of EC cells in culture treated with gemcitabine after $72 \mathrm{~h}$. (A) NT2 cells. (B) 2102 EP cells. Note the reduced cell growth rate in hypoxia, which did not correlate with drug resistance. OD - optical density. nm - nanometers.

mide, and carboplatin, all used in standard chemotherapy regimens for TGCTs, and of paclitaxel, gemcitabine, and oxaliplatin, drugs now used in patients with cisplatin-refractory disease (Bokemeyer et al, 1996; Motzer et al, 2000; Einhorn, 2002; Kollmannsberger et al, 2002; Shelley et al, 2002) was studied in three different cell lines. All drugs were less effective under hypoxic conditions. In contrast to data obtained from other tumour entities (Kennedy et al, 1983; Luk et al, 1990; Yamagata et al, 1992; Sanna and Rofstad, 1994; Liang, 1996; Skov et al, 1998; Kovacs et al, 1999), this also held true for the use of cisplatin and mitomycin C in GCTs.

Particularly for mitomycin C, this finding is unexpected. Mitomycin $\mathrm{C}$ has been postulated to be an alkylating agent requiring reduction for activity, and anaerobic conditions enhance the cytotoxicity (Iyer and Szybalski, 1964). Rockwell (1986) showed that the cytotoxic effects of mitomycin $\mathrm{C}$ increased at acidic $\mathrm{pH}$ culture conditions in vitro. At a low $\mathrm{pH}(6.0-7.0)$, mitomycin $\mathrm{C}$ can be spontaneously reduced to an alkylating species without enzymatic activation, while, in the physiologic $\mathrm{pH}$ range (7.0-7.4), the cytotoxic effect of mitomycin $\mathrm{C}$ does not vary with the $\mathrm{pH}$ (Rockwell, 1986). In our system, the $\mathrm{pH}$ of the medium of untreated cells under hypoxia was in the physiologic range and did not change after $72 \mathrm{~h}$, probably due to the slower growth of NT2 cells or the growth arrest of NCCIT cells in hypoxia.
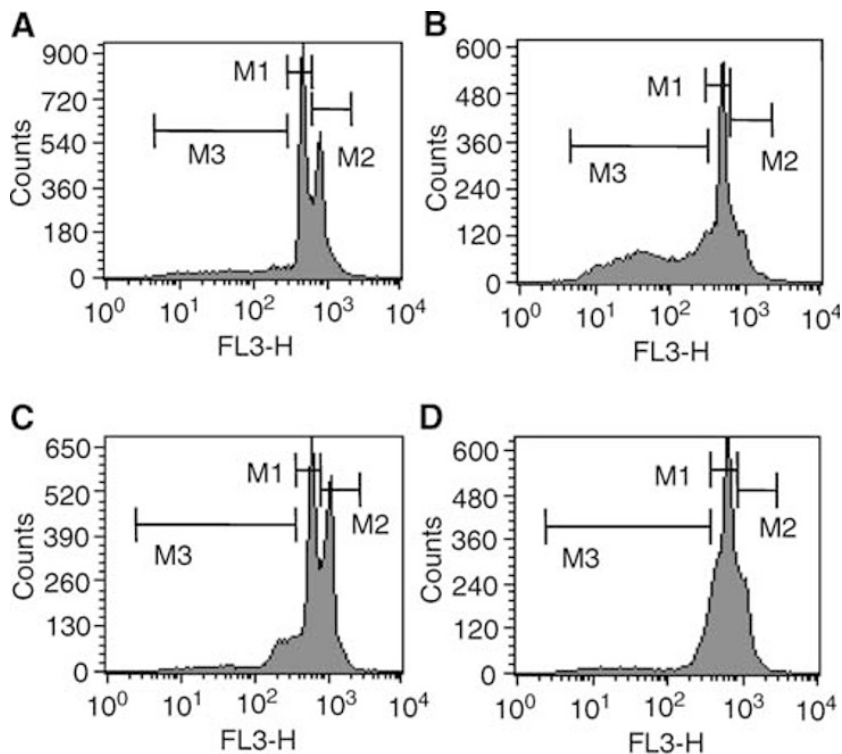

Figure 4 Histogram plots of the cell cycle analysis of NT2 (A) and NCCIT cells $(\mathbf{C})$ in normoxia and NT2 (B) and NCCIT (D) in hypoxia after $48 \mathrm{~h}$ by flow-cytometric staining with PI. MI - Gl phase. M2 - G2 phase. M3 - apoptotic cells.

Compared to that, the $\mathrm{pH}$ of the medium of untreated normoxic cells decreased to acidic $\mathrm{pH}$ values between 6.0 and 7.0. However, mitomycin $\mathrm{C}$ was also less effective in hypoxia at an experimentally acidified $\mathrm{pH}$ (6.5). Furthermore, this study demonstrates that mitomycin $\mathrm{C}$ already exhibited a significant cytotoxic effect in TGCT cells during hypoxia with $1 \% \mathrm{pO}_{2}$ in vitro. In contrast to these results, Kennedy et al (1980) and Teicher et al (1981) achieved a selective toxicity of mitomycin $\mathrm{C}$ in mouse mammary tumour cells using considerable lower $(<0.1 \%)$ oxygen tensions prior to the addition of the drug. As mitomycin $\mathrm{C}$ acts in a cell cycle-dependent manner, the pronounced effect of hypoxia on proliferation and the observed G1/S arrest might prevail the bioreductive activation in our model.

These findings may also serve as a rationale for clinical studies on tumour oxygenation and response to chemotherapy in GCT patients. A previous retrospective analysis of haemoglobin values at the end of treatment and prognosis in GCT patients undergoing sequential dose intensive chemotherapy has indicated that patients with a haemoglobin level $<10.5 \mathrm{~g} \mathrm{dl}^{-1}$ postchemotherapy may have a significantly inferior outcome (Bokemeyer et al, 2002). Tumour oxygenation depends, among other factors, on the haemoglobin content of the blood. Hence, correction of tumourassociated anaemia - for example, with recombinant erythropoietin - may improve the $p \mathrm{O}_{2}$ in tumour tissue. The use of erythropoietin in anaemic cancer patients has been studied to reduce the need for transfusions and to improve the quality of life (QOL). In patients with head and neck tumours receiving erythropoietin, an improved outcome of treatment has also been suggested. Based on the results presented, the hypothesis should be tested as to whether raising the haemoglobin level in patients with GCTs undergoing chemotherapy might improve the treatment outcome.

The presented data also allow for some conclusions regarding the mechanisms involved in the relative drug resistance induced by hypoxia. The impact of hypoxia on chemosensitivity depended strongly on the cell line. The least effect was evident in NT2, the only cells that kept proliferating under hypoxic conditions. The two remaining cell lines showed a far more pronounced relative drug resistance in hypoxia. These findings allow for two different interpretations: NT2 could be less sensitive for the effect of 
hypoxia in general, that is, hypoxia-induced effects are less pronounced. Alternatively, despite similar changes in hypoxiainduced gene expression overall, only the effect on cell proliferation differs between the cells. The latter interpretation would point to the effect on proliferation as the main factor determining the relative effect of hypoxia on drug sensitivity. However, there was no strict correlation between cell proliferation and cytotoxic effect indicating relevant influences of factors other than proliferation.

The hypoxia induced relative resistance to cytotoxic agents depended only partly on the specific substance. Despite the different modes of action - for example, for gemcitabine introduction of single-strand DNA breaks, and for etoposide and irinotecan topoisomerase inhibition - the relative increase in resistance to these drugs during hypoxia was similar. So far, the potential relevant resistance mechanisms for some of the drugs with similar behaviour under hypoxic and normoxic conditions have been considered to be nonoverlapping. Of the substances tested, only etoposide is transported out of the cells by $\mathrm{P}$ glycoprotein (P-gp). Paclitaxel - a stabiliser of $\beta$-microtubulin polymerisation disrupting the formation of the normal mitotic spindles and thereby blocking mitosis (Horwitz, 1992) - is independent of P-gp (Lautier et al, 1996). Therefore, a HIF-1 $\alpha$ mediated induction of P-gp under hypoxic conditions - as recently proposed by Wartenberg et al (2003) - can be ruled out as a dominating resistance mechanism in hypoxia in our setting. Bleomycin causes DNA breaks through direct binding to DNA. This process depends on oxygen and produces reactive oxidative species (ROS), which may also play a role in the toxicity of bleomycin (Sikic, 1986). P53 does not seem to play an essential role in drug resistance under hypoxic conditions in the models chosen here, as NCCIT cells express mutant p53, and NT2 and 2102 EP express wild-type p53 (Burger et al, 1997). The broad spectrum of substances with unrelated modes of action and potential means of resistance suggests that rather universally active mechanisms or coactivation of several pathways confer resistance under hypoxic condition. Kinoshita et al (2001) reported that cancer cells might obtain resistance to apoptosis once they have survived hypoxia. The underlying mechanism remains elusive so far. Other investigators have also suggested that tumour cells acquire antiapoptotic features and will be selected by hypoxia (Kim et al, 1997).

In summary, this extensive in vitro study using several cytotoxic drugs in three TGC tumour cell lines shows the importance of normoxic conditions regarding treatment sensitivity in this tumour model for all chemotherapy agents investigated.

\section{ACKNOWLEDGEMENTS}

This study was supported by a grant from the Else-UebelmesserStiftung. We thank Professor Peter Vaupel (Institute of Physiology and Pathophysiology, University of Mainz) for the critical review of the manuscript and Dr Martin Weinmann (Department of Radiation Oncology, University of Tuebingen) for reading the manuscript and helpful discussions.

\section{REFERENCES}

Becker A, Stadler P, Lavey RS, Haensgen G, Kuhnt T, Lautenschlaeger C, Feldmann HJ, Molls M, Dunst J (2000) Severe anemia is associated with poor tumor oxygenation in head and neck squamous cell carcinomas. Int J Radiat Oncol Biol Phys 46: 459-466

Bokemeyer C, Beyer J, Metzner B, Ruther U, Harstrick A, Weissbach L, Kohrmann U, Verbeek W, Schmoll HJ (1996) Phase II study of paclitaxel in patients with relapsed or cisplatin-refractory testicular cancer. Ann Oncol 7: $31-34$

Bokemeyer C, Oechsle K, Hartmann JT, Schoffski P, Schleucher N, Metzner B, Schleicher J, Kanz L (2002) Treatment-induced anaemia and its potential clinical impact in patients receiving sequential high dose chemotherapy for metastatic testicular cancer. $\mathrm{Br} J$ Cancer 87: $1066-1071$

Brown JM, Giaccia AJ (1998) The unique physiology of solid tumors: opportunities (and problems) for cancer therapy. Cancer Res 58: 1408 1416

Burger H, Nooter K, Boersma AW, Kortland CJ, Stoter G (1997) Lack of correlation between cisplatin-induced apoptosis, p53 status and expression of Bcl-2 family proteins in testicular germ cell tumour cell lines. Int $J$ Cancer 73: $592-599$

Cella D, Zagari MJ, Vandoros C, Gagnon DD, Hurtz HJ, Nortier JW (2003) Epoetin alfa treatment results in clinically significant improvements in quality of life in anemic cancer patients when referenced to the general population. J Clin Oncol 21: 366-373

Comerford KM, Wallace TJ, Karhausen J, Louis NA, Montalto MC, Colgan SP (2002) Hypoxia-inducible factor-1-dependent regulation of the multidrug resistance (MDR1) gene. Cancer Res 62: 3387-3394

Cooke SP, Boxer GM, Lawrence L, Pedley RB, Spencer DI, Begent RH, Chester KA (2001) A strategy for antitumor vascular therapy by targeting the vascular endothelial growth factor: receptor complex. Cancer Res 61: $3653-3659$

Einhorn LH (2002) Chemotherapeutic and surgical strategies for germ cell tumors. Chest Surg Clin N Am 12: 695-706

Goldstein LJ (1996) MDR1 gene expression in solid tumours. Eur J Cancer 6: $1039-1050$

Hoeckel M, Schlenger K, Aral B, Mitze M, Schaeffer U, Vaupel P (1996) Association between tumor hypoxia and malignant progression in advanced cancer of the uterine cervix. Cancer Res 56: 4509-4515
Hoeckel M, Vaupel P (2001) Tumor hypoxia: definitions and current clinical, biologic, and molecular aspects. J Natl Cancer Inst 93: $266-276$

Horwitz SB (1992) Mechanism of action of taxol. Trends Pharmacol Sci 13: $134-136$

Iyer VN, Szybalski W (1964) Mitomycins and porfiromycin: chemical mechanism of activation and cross-linking of DNA. Science 145: 55

Kennedy KA, Rockwell S, Sartorelli AC (1980) Preferential activation of mitomycin $\mathrm{C}$ to cytotoxic metabolites by hypoxic tumor cells. Cancer Res 40: $2356-2360$

Kennedy KA, Siegfried JM, Sartorelli AC, Tritton TR (1983) Effects of anthracyclines on oxygenated and hypoxic tumor cells. Cancer Res 43: $54-59$

Kim CY, Tsai MH, Osmanian C, Graeber TG, Lee JE, Giffard RG, DiPaolo JA, Peehl DM, Giaccia AJ (1997) Selection of human cervical epithelial cells that possess reduced apoptotic potential to low-oxygen conditions. Cancer Res 57: 4200 - 4204

Kinoshita M, Johnson DL, Shatney CH, Lee YL, Mochizuki H (2001) Cancer cells surviving hypoxia obtain hypoxia resistance and maintain antiapoptotic potential under reoxygenation. Int J Cancer 91: 322-326

Kollmannsberger C, Rick O, Derigs HG, Schleucher N, Schoffski P, Beyer J, Schoch R, Sayer HG, Gerl A, Kuczyk M, Spott C, Kanz L, Bokemeyer C (2002) Activity of oxaliplatin in patients with relapsed or cisplatinrefractory germ cell cancer: a study of the German Testicular Cancer Study Group. J Clin Oncol 20: $2031-2037$

Kondo J, Arii S, Furutani M, Isigami SI, Mori A, Onodera H, Chiba T, Imamura M (2000) Implication of vascular endothelial growth factor and p53 status for angiogenesis in noninvasive colorectal carcinoma. Cancer 88: $1820-1827$

Kondo A, Safaei R, Mishima M, Niedner H, Lin X, Howell SB (2001) Hypoxia-induced enrichment and mutagenesis of cells that have lost DNA mismatch repair. Cancer Res 61: 7603-7607

Koukourakis MI, Giatromanolaki A, Skarlatos J, Corti L, Blandamura S, Piazza M, Gatter KC, Harris AL (2001) Hypoxia inducible factor (HIF-1a and HIF-2a) expression in early esophageal cancer and response to photodynamic therapy and radiotherapy. Cancer Res 61: $1830-1832$ 
Kovacs MS, Hocking DJ, Evans JW, Siim BG, Wouters BG, Brown JM (1999) Cisplatin anti-tumor potentiation by tirapazamine results from a hypoxia-dependent cellular sensitization to cisplatin. $\mathrm{Br} J$ Cancer 80: $1245-1251$

Lautier D, Canitrot Y, Deeley RG, Cole SP (1996) Multidrug resistance mediated by the multidrug resistance protein (MRP) gene. Biochem Pharmacol 52: $967-977$

Liang BC (1996) Effects of hypoxia on drug resistance phenotype and genotype in human glioma cell lines. J Neurooncol 29: 149-155

Lin X, Ramamurthi K, Mishima M, Kondo A, Christen RD, Howell SB (2001) p53 modulates the effect of loss of DNA mismatch repair on the sensitivity of human colon cancer cells to the cytotoxic and mutagenic effects of cisplatin. Cancer Res 61: 1508-1516

Lin X, Ramamurthi K, Mishima M, Kondo A, Howell SB (2000) p53 interacts with the DNA mismatch repair system to modulate the cytotoxicity and mutagenicity of hydrogen peroxide. Mol Pharmacol 58: $1222-1229$

López-Barneo J, Pardal R, Ortega-Sáenz P (2001) Cellular mechanisms of oxygen sensing. Annu Rev Physiol 63: 259-287

Luk CK, Veinot-Debrot L, Tjan E, Tannock IF (1990) Effect of transient hypoxia on sensitivity to doxorubicin in human and murine cell lines. $J$ Natl Cancer Inst 82: 684-692

Mayer F, Honecker F, Looijenga LHJ, Bokemeyer C (2003) Towards understanding of the biological basis of chemotherapy response in germ cell tumors. Ann Oncol 14: 825-832

Mottram JC (1931) A factor of importance in the radio-sensitivity of tumours. Br J Radiol 9: 606-614

Motzer RJ, Chou TC, Schwartz L, Bosl GJ, Bajorin DF, Hutter H (1995) Paclitaxel in germ cell cancer. Semin Oncol 22: $12-15$

Motzer RJ, Sheinfeld J, Mazumdar M, Bains M, Mariani T, Bacik J, Bajorin D, Bosl GJ (2000) Paclitaxel, ifosfamide, and cisplatin second-line therapy for patients with relapsed testicular germ cell cancer. J Clin Oncol 18: $2413-2418$

Nicoletti I, Migliorati G, Pagliacci MC, Grignani F, Riccardi C (1991) A rapid and simple method for measuring thymocyte apoptosis by propidium iodide staining and flow cytometry. J Immunol Methods 139: $271-279$

Nordsmark M, Overgaard M, Overgaard J (1996) Pretreatment oxygenation predicts radiation response in advanced aquamous cell carcinoma of the head and neck. Radiother Oncol 41: $31-39$

Rockwell S (1986) Effect of some proliferative and environmental factors on the toxicity of mitomycin $\mathrm{C}$ to tumor cells in vitro. Int J Cancer 38: $229-235$
Sanna K, Rofstad EK 1994 Hypoxia-induced resistance to doxorubicin and methotrexate in human melanoma cell lines in vitro. Int J Cancer 58: $258-262$

Semenza GL (2000) Hypoxia, clonal selection, and the role of HIF-1 in tumor progression. Crit Rev Biochem Mol Biol 35: 71-103

Shelley MD, Burgon K, Mason MD (2002) Treatment of testicular germ-cell cancer: a Cochrane evidence-based systematic review. Cancer Treat Rev 28: $237-253$

Sieuwerts AM, Klijn JG, Peters HA, Foekens JA (1995) The MTT tetrazolium salt assay scrutinized: how to use this assay reliably to measure metabolic activity of cell cultures in vitro for the assessment of growth characteristics, IC50-values and cell survival. Eur J Clin Chem Clin Biochem 33: $813-823$

Sikic BI (1986) Biochemical and cellular determinants of bleomycin cytotoxicity. Cancer Surv 5: $81-91$

Skov KA, Adomat H, Farrell NP, Matthews JB (1998) Assessment of toxicity of bis-platinum complexes in hypoxic and aerobic cells. Anticancer Drug Des 13: $207-220$

Teicher BA, Kowal CD, Kennedy KA, Sartorelli AC (1981) Enhancement by hyperthermia of the in vitro cytotoxicity of mitomycin $\mathrm{C}$ toward hypoxic tumor cells. Cancer Res 41: 1096-1099

Vaupel P, Hoeckel M (1998) Oxygenation of human tumors. In Blood Perfusion and Microenvironment of Human Tumors Molls M, Vaupel P (eds) Berlin, Germany: Springer

Vaupel P, Kelleher DK, Hoeckel M (2001) Oxygen status of malignant tumors: pathogenesis of hypoxia and significance for tumor therapy. Semin Oncol 28: $29-35$

Wang N, Perkins KL, Bronson DL, Fraley EE (1981) Cytogenetic evidence for premeiotic transformation of human testicular cancers. Cancer Res 41: $2135-2140$

Wartenberg M, Ling FC, Muschen M, Klein F, Acker H, Gassmann M, Petrat K, Putz V, Hescheler J, Sauer H (2003) Regulation of the multidrug resistance transporter P-glycoprotein in multicellular tumor spheroids by hypoxia-inducible factor-1 and reactive oxygen species. FASEB J 17: $503-505$

Yamagata M, Kanematsu T, Matsumata T, Utsunomiya T, Ikada Y, Sugimachi K (1992) The difference in chemosensitivity to antineoplastic agents of human hepatocellular carcinoma cells under normo-oxygenated or hypoxic conditions. Eur J Surg Oncol 18: 379-382

Zhong H, De Marzo AM, Laughner E, Lim M, Hilton DA, Zagzag D, Buechler P, Isaacs WB, Semenza GL, Simons JW (1999) Overexpression of hypoxia-inducible factor $1 \alpha$ in common human cancers and their metastases. Cancer Res 59: 5830-5835 